\title{
REVIEW
}

\section{Infective disorders of the gastrointestinal tract}

\author{
L W Lamps \\ Department of Pathology, University of Arkansas for Medical Sciences, Little Rock, AR, USA
}

Lamps L W

(2007) Histopathology 50, 55-63

\section{Infective disorders of the gastrointestinal tract}

Gastrointestinal infections are a major cause of morbidity and mortality worldwide. Infectious organisms are often recovered by microbiological methods, but surgical pathologists may play a very valuable role in diagnosis. This review will focus on infective disorders of the gastrointestinal tract with an emphasis on enterocolitides caused by food- and water-borne path- ogens. Diagnostic histological features of selected enteric infections will be emphasized, including those that mimic other inflammatory conditions of the gut (such as ischaemia or idiopathic inflammatory bowel disease), along with available diagnostic methods that can aid in diagnosis.

Keywords: bacteria, diarrhoea, food-borne infection, infectious enterocolitis, inflammatory bowel disease

Abbreviations: ASLC, acute self-limited colitis; EHEC, enterohaemorrhagic E. coli; PCR, polymerase chain reaction; YE, Yersinia enterocolitica; YP, Yersinia pseudotuberculosis

\section{Introduction}

Infective disorders of the gastrointestinal tract are a major cause of morbidity and mortality worldwide. As numbers of transplant patients and those with other immunocompromising conditions increase, and as global urbanization and transcontinental travel become more frequent, the surgical pathologist must be familiar with infectious diseases that were previously encountered only infrequently.

The pathologist's goal in evaluating a gastrointestinal biopsy for infectious colitis is twofold. First, acute self-limited and/or infectious processes must be differentiated from chronic idiopathic inflammatory bowel disease (ulcerative colitis or Crohn's disease). ${ }^{1-4}$ Second, dedicated attempts must be made to identify the infecting organism(s). The surgical pathologist's ability to diagnose infectious processes in tissue sections has grown exponentially with the advent of new

Address for correspondence: Laura W Lamps MD, Department of Pathology, University of Arkansas for Medical Sciences, 4301 W. Markham, Slot 517, Little Rock, AR 72205, USA.

e-mail: lampslauraw@uams.edu histochemical stains, immunohistochemistry, in situ hybridization and numerous other molecular methodologies. As these techniques have developed, our understanding of the correlation between histological patterns of inflammation and specific organisms or groups of organisms has also increased.

The majority of enteric infections are self-limited. Those patients that undergo endoscopic biopsy often have chronic or debilitating diarrhoea, systemic symptoms, or a history of immunocompromise or other significant clinical scenarios. A discussion with the gastroenterologist regarding exact symptomatology and colonoscopic findings, as well as facts including travel history, food intake (such as sushi or poorly cooked beef), sexual practices and immune status, can greatly aid in the evaluation of a biopsy for infectious diseases. ${ }^{5}$ As many infective disorders of the gastrointestinal tract are acquired through contaminated food, this review will focus primarily on enterocolitides caused by food-borne bacteria. In addition, infectious processes that mimic or cause ischaemia and those that mimic chronic idiopathic inflammatory bowel disease will be emphasized, along with ancillary techniques that aid in diagnosis. 
Table 1. Classification of selected infective disorders of the gastrointestinal tract by histological pattern

\begin{tabular}{|c|c|c|c|c|c|c|c|}
\hline $\begin{array}{l}\text { Minimal or no } \\
\text { inflammatory } \\
\text { change }\end{array}$ & $\begin{array}{l}\text { Acute } \\
\text { self-limited } \\
\text { colitis pattern }\end{array}$ & $\begin{array}{l}\text { Pseudo- } \\
\text { membranous } \\
\text { pattern }\end{array}$ & $\begin{array}{l}\text { Predominantly } \\
\text { granulomatous }\end{array}$ & $\begin{array}{l}\text { Predominantly } \\
\text { lympho- } \\
\text { histiocytic }\end{array}$ & $\begin{array}{l}\text { Marked } \\
\text { architectural } \\
\text { distortion }\end{array}$ & $\begin{array}{l}\text { Ischaemic } \\
\text { pattern }\end{array}$ & $\begin{array}{l}\text { Prominent } \\
\text { necrosis } \\
\text { and ulceration }\end{array}$ \\
\hline Vibrio cholerae & Shigella sp. & $\begin{array}{l}\text { Entero- } \\
\text { haemorrhagic } \\
\text { E. coli }\end{array}$ & Yersinia sp. & $\begin{array}{l}\text { Salmonella } \\
\text { typhi }\end{array}$ & $\begin{array}{l}\text { Salmonella } \\
\text { typhi }\end{array}$ & $\begin{array}{l}\text { Entero- } \\
\text { haemorrhagic } \\
\text { E. coli }\end{array}$ & $\begin{array}{l}\text { Entero- } \\
\text { haemorrhagic } \\
\text { E. coli }\end{array}$ \\
\hline $\begin{array}{l}\text { Enteropathogenic } \\
\text { E. coli }\end{array}$ & $\begin{array}{l}\text { Campylo- } \\
\text { bacter sp. }\end{array}$ & & & & Shigella sp. & $\begin{array}{l}\text { Clostridium } \\
\text { perfringens }\end{array}$ & \\
\hline $\begin{array}{l}\text { Enteroadherent } \\
\text { E. coli }\end{array}$ & Aeromonas & $\begin{array}{l}\text { Occasionally } \\
\text { Shigella }\end{array}$ & & & $\begin{array}{l}\text { Aeromonas } \\
\text { (occasionally) }\end{array}$ & & $\begin{array}{l}\text { Clostridium } \\
\text { perfringens }\end{array}$ \\
\hline $\begin{array}{l}\text { Enteric viruses } \\
\text { Staphylococcus } \\
\text { aureus }\end{array}$ & $\begin{array}{l}\text { Non-typhoid } \\
\text { Salmonella sp. } \\
\text { occasionally } \\
\text { Salmonella } \\
\text { typhi }\end{array}$ & & & & & & \\
\hline
\end{tabular}

\section{General classification of food-borne infections by histological pattern}

Despite the vast number of food-borne infections that affect the gastrointestinal tract, the spectrum of histological findings produced by a given organism can be generally categorized in one of the following ways (see Table 1):

1 Those producing minimal or no histological changes (e.g. Vibrio species and many enteric viruses).

2 Those producing a non-specific acute self-limited/ infectious colitis (ASLC) pattern (e.g. Campylobacter jejuni); this is one of the most common inflammatory patterns in enteric infections. ${ }^{1-4}$

3 Those producing suggestive or diagnostic histological features (e.g. pseudomembranes, granulomas, or visible organisms).

Acute infectious-type colitis characteristically features intact crypt architecture with neutrophilic infiltrates in the crypt epithelium. The lamina propria may be hypercellular, containing a mix of lymphocytes, histiocytes and neutrophils; plasma cells are generally not prominent, and basal plasma cells should not be seen in acute infectious-type colitis as these are a marker of chronicity. Crypt abscesses and granulomas associated with damaged crypts may also be seen. There is often damage also to the surface epithelium. ${ }^{2-4}$ Since patients often do not come to endoscopy until several weeks after onset of symptoms, pathologists frequently do not see the classic histological features of acute infectious-type colitis. This is important, as the resolving phase of infectious colitis is more challenging to diagnose, as one may find only occasional foci of

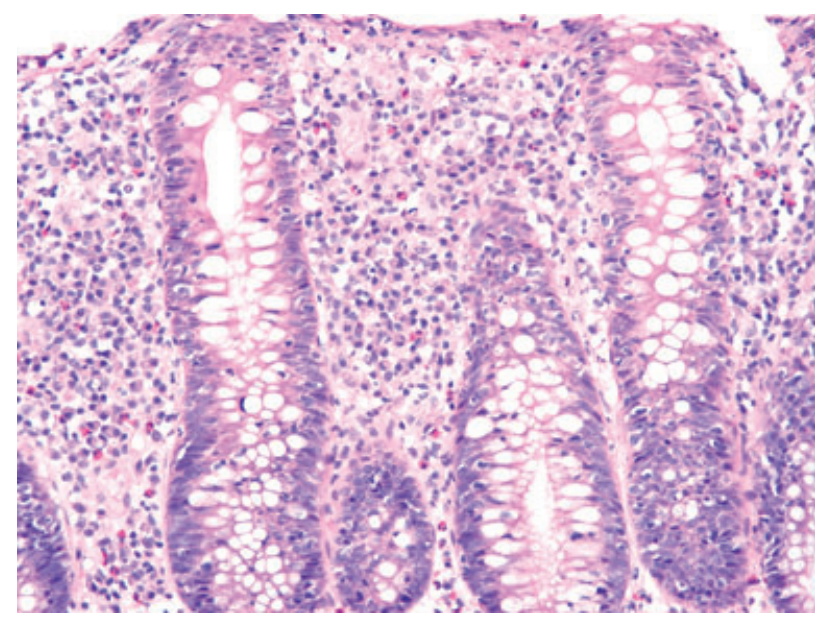

Figure 1. Numerous plasma cells in the lamina propria and increased intraepithelial lymphocytes may be seen in resolving infectious colitis, mimicking lymphocytic colitis (H\&E).

neutrophilic cryptitis with a patchy increase in lamina propria inflammation, which may contain numerous plasma cells and increased intraepithelial lymphocytes (Figure 1). As these features can also be seen in smoldering Crohn's disease and lymphocytic colitis, it is important to know the patient's symptoms and, ideally, culture results as this differential diagnosis may be difficult to resolve on histological grounds alone.

\section{Selected specific food- and/or water-borne gastrointestinal infective disorders}

Escherichia coli, Campylobacter, Salmonella, Yersinia, Shigella and enteric viruses represent the most common 
food-borne pathogens worldwide. ${ }^{5}$ It is important to note, when reviewing a patient's history, that many organisms associated with food-borne illness can also be transmitted through water or unpasteurized milk. ${ }^{5}$ Naturally occurring water-borne outbreaks of Sa. typhi, enterohaemorrhagic E. coli and Norwalk virus have been reported, usually due to improperly operated water treatment plants. Several other organisms (including anthrax, Francisella tularensis and Shigella) are particularly stable in water due to chlorine tolerance. ${ }^{6}$ Although these organisms are sometimes recovered by culture, surgical pathologists may play a very valuable role in diagnosis, particularly when clinicians have failed to obtain cultures prior to initiation of antibiotic therapy.

In addition, many of the food- and water-borne gastrointestinal infective diseases discussed below mimic other entities that are commonly encountered in surgical pathology practice, such as ischaemic colitis or idiopathic inflammatory bowel disease.

\section{CAMPYLOBACTER SPECIES}

These Gram-negative bacteria are a major cause of naturally occurring diarrhoea worldwide. Campylobacter jejuni and $C$. coli are most frequently associated with human enteric disease. ${ }^{7,8}$ Campylobacter may contaminate poultry, beef, veal, pork, water and milk, and are also transmitted by the faecal-oral route. The infective dose is low (as few as 500 organisms can cause symptomatic disease). Patients typically present with fever, malaise, abdominal pain and watery diarrhoea that often contains blood and faecal leucocytes. ${ }^{8-10}$ Symptoms generally present within 15 days of exposure and last for 4-10 days. Most infections are self-limited, particularly in otherwise healthy patients, although relapse is common. Of note, both reactive arthropathy and Guillain-Barré syndrome may be associated with Campylobacter infection. $^{8}$

Endoscopic findings are non-specific and include friable colonic mucosa with associated erythema and haemorrhage. Histological examination shows features of acute self-limited colitis, including a neutrophilic infiltrate in the lamina propria, often most prominent in the mid-to-upper crypts; cryptitis; and scattered crypt abscesses (Figure 2). Architecture overall is preserved, although mild crypt distortion is occasionally noted. ${ }^{7-10}$ The histological differential diagnosis includes other infectious entities that produce the ASLC pattern.

The mainstay of laboratory diagnosis is culture from stool or blood. Preliminary diagnosis may be made by

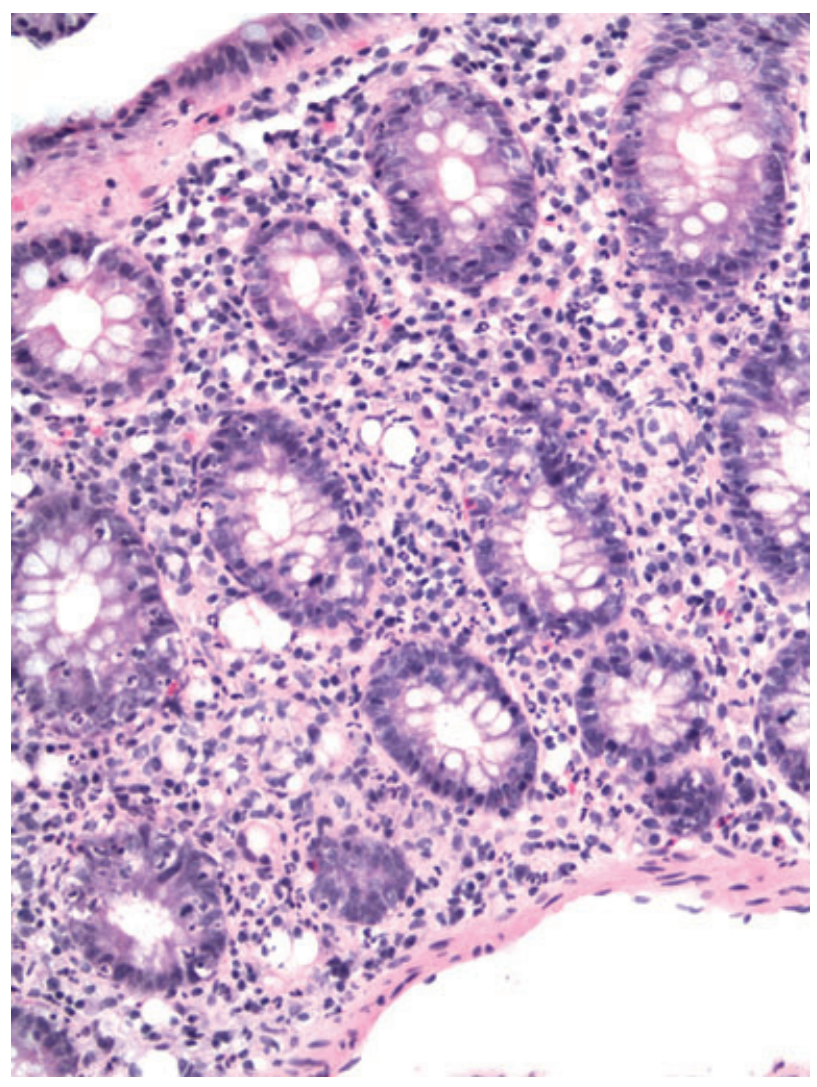

Figure 2. Culture and polymerase chain reaction-proven Campylobacter colitis featuring well-developed neutrophilic cryptitis, a neutrophilic infiltrate in the lamina propria and preservation of crypt architecture (H\&E).

detection of organisms in fresh stool smears by darkfield microscopy. Excellent molecular techniques exist, but are not widely available for clinical use. ${ }^{7}$

\section{SALMONELLA SPECIES}

These Gram-negative bacilli are particularly prevalent in underdeveloped countries where sanitation is poor and dairy and water supplies are contaminated with the organism. However, Salmonella are also an important cause of sporadic food poisoning in developed countries. They are present in water, meat, dairy products, egg products and occasionally vegetables and fruits; they may survive partial cooking. ${ }^{5}$

The discussion of Salmonella species is historically divided into typhoid and non-typhoid species. Patients with typhoid (enteric) fever, usually caused by $S a$. typhi, typically present with fever that rises over several days, abdominal pain and headache. Abdominal rash ('rose spots'), delirium, hepatosplenomegaly and leukopenia are also fairly common. The diarrhoea, 
which begins in the second or third week of infection, is initially watery but may progress to severe gastrointestinal bleeding and perforation. Non-typhoid species (e.g. Sa. enteritidis, Sa. typhimurium, Sa. muenchen, Sa. anatum, Sa. paratyphi and Sa. give) generally cause a milder, often self-limited gastroenteritis with vomiting, nausea, fever and watery diarrhoea. ${ }^{11-15}$ The infective dose is relatively low (approximately $10^{2}-10^{3}$ organisms may cause human disease). Although most Salmonella infections in developed countries resolve with antibiotics and supportive care, enteric infection may progress to septicaemia and death, particularly in the elderly, the very young or patients who are debilitated. Delayed treatment is associated with higher mortality. ${ }^{12}$

Any level of the gastrointestinal tract may be affected, but the ileum, appendix and right colon are preferentially involved. The bowel wall is thickened, with raised nodules corresponding to hyperplastic Peyer patches. Apthoid ulcers overlying Peyer patches, linear ulcers, discoid ulcers or full thickness ulceration and necrosis often occur as disease progresses. Perforation and toxic megacolon may be seen, as can suppurative mesenteric lymphadenitis. Peyer patches become hyperplastic, followed by acute inflammation of the superficial overlying epithelium. Eventually the lymphoid follicles are infiltrated and obliterated by macrophages. The histiocyte is the predominant inflammatory cell in typhoid fever; admixed lymphocytes and plasma cells are seen, but neutrophils are typically not prominent. The ulcers are characteristically very deep, with the base at the muscularis propria. ${ }^{11-15}$ Architectural distortion severe enough to mimic ulcerative colitis or Crohn's disease may be present (Figure 3).

With non-typhoid species, the gross findings are often milder. The lesions can be focal, and occasionally the mucosa is grossly normal or only mildly hyperaemic and oedematous. The pathological features are most often those of acute self-limited colitis, although severe cases may have significant crypt distortion. ${ }^{14}$

Cultures are the mainstay of Salmonella diagnosis. The differential diagnosis includes other enteric bacterial pathogens as well as Crohn's disease and ulcerative colitis. ${ }^{13,14}$ Clinically, the incubation period of Salmonella infection is longer (10-15 days) than with similar enteric pathogens. Salmonella infection often lacks significant numbers of neutrophils in comparison with other pathogens (as well as idiopathic inflammatory bowel disease), and granulomas are unusual in salmonellosis. Crypt distortion is generally more pronounced in ulcerative colitis than in salmonellosis. Clinical presentation and stool cultures may be very helpful in resolving the differential.

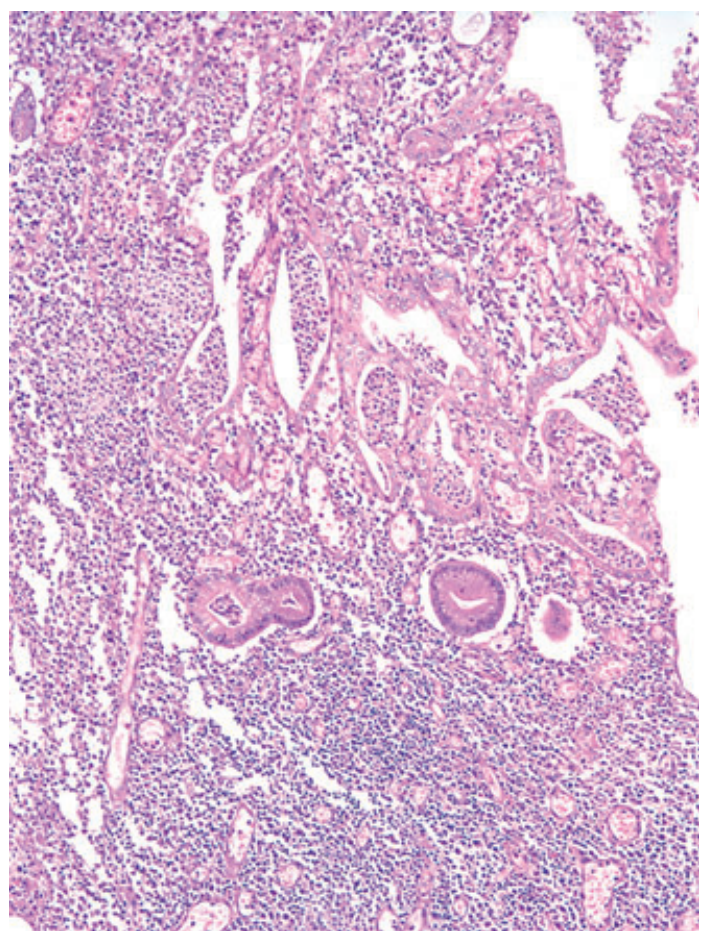

Figure 3. Salmonella typhi infection featuring mucosal ulceration, crypt abscesses and marked architectureal distortion, overlying a Peyer patch (H\&E). Case courtesy of Dr A. Brian West.

\section{SHIGELLA SPECIES}

Shigella are virulent, invasive Gram-negative bacilli that cause severe bloody diarrhoea. Shigella dysenteriae is the most common species isolated, although Sh. sonnei and Sh. flexneri are increasingly reported in the USA. They are generally ingested from faecally contaminated water, but person-to-person transmission is also possible. The infective dose is very low (as few as 10-100 organisms in Sh. dysenteriae type 1). ${ }^{16}$ Infants and small children, homosexual males and malnourished or debilitated patients are most commonly affected in developed countries. Like salmonellosis, the gross and microscopic features of shigellosis may mimic chronic idiopathic inflammatory bowel disease. Symptoms include abdominal pain, fever and watery diarrhoea, followed by bloody diarrhoea that is often mucoid and/or purulent. Constitutional symptoms are common. ${ }^{16,17}$ Perforation and haemolytic-uraemic syndrome have been described. Most studies of mortality in shigellosis were performed in underdeveloped nations, and figures range from 2 to $10 \%$. Mortality is significantly higher $(>20 \%)$ if patients develop sepsis. ${ }^{16}$

The large bowel is typically affected (often the left colon most severely), but the ileum may also be involved. The mucosa is haemorrhagic, and variably 
ulcerated, sometimes with pseudomembranous exudates. ${ }^{18}$ Early shigellosis has features of ASLC with cryptitis, crypt abscesses (often superficial) and ulceration. Apthoid ulcers similar to Crohn's disease are variably present. As disease continues, mucosal destruction develops with many neutrophils (as well as other inflammatory cells) in the lamina propria. Marked architectural distortion is common, leading to diagnostic confusion with chronic idiopathic inflammatory bowel disease. ${ }^{17}$

Stool culture is essential to diagnosis, but multiple cultures may be necessary to recover the organism, for it is fastidious and dies off quickly. Polymerase chain reaction (PCR), DNA probes and serological studies are also available. ${ }^{16}$ The differential diagnosis of early shigellosis is primarily that of other infections, particularly enteroinvasive E. coli and Clostridium difficile. Later on in the course of the disease, it may be extremely difficult to distinguish shigellosis from Crohn's disease or ulcerative colitis both endoscopically and histologically. ${ }^{1}$ Stool cultures and clinical history may be very helpful in resolving the differential.

\section{YERSINIA SPECIES}

Yersinia enterocolitica (YE) and Y. pseudotuberculosis (YP) are the most common causes of bacterial enteritis in Western and Northern Europe, and increasing numbers of cases have been documented in North America and Australia. Yersinia have been found in chicken, fish, shellfish, swine, cattle, milk, ice cream, beef, lamb, poultry, pork, ham and water. ${ }^{5}$ Infection with either species may cause abdominal pain, diarrhoea and symptoms and signs of appendicitis, enterocolitis or an acute abdomen. Associated mesenteric lymphadenopathy is frequent. Most infections are selflimited; however, immunocompromised and debilitated patients, as well as patients on deferoxamine or with iron overload, are at risk of more serious disease. ${ }^{19}$

Yersinia preferentially involves the ileum, right colon and appendix. Grossly, involved bowel has a thickened, oedematous wall with nodular inflammatory masses centred around Peyer patches. Apthoid and linear ulcers may be present. Both suppurative and granulomatous patterns of inflammation can be seen, and a mixture of the two is common..$^{20-22}$ Recent studies have shown that there is significant overlap between the histological features of YE and YP infection and that either species may show lymphoid hyperplasia, epithelioid granulomas with prominent lymphoid cuffing (Figure 4), transmural lymphoid aggregates, giant cells, mucosal ulceration, cryptitis and concomitant lymph node involvement. ${ }^{20}$

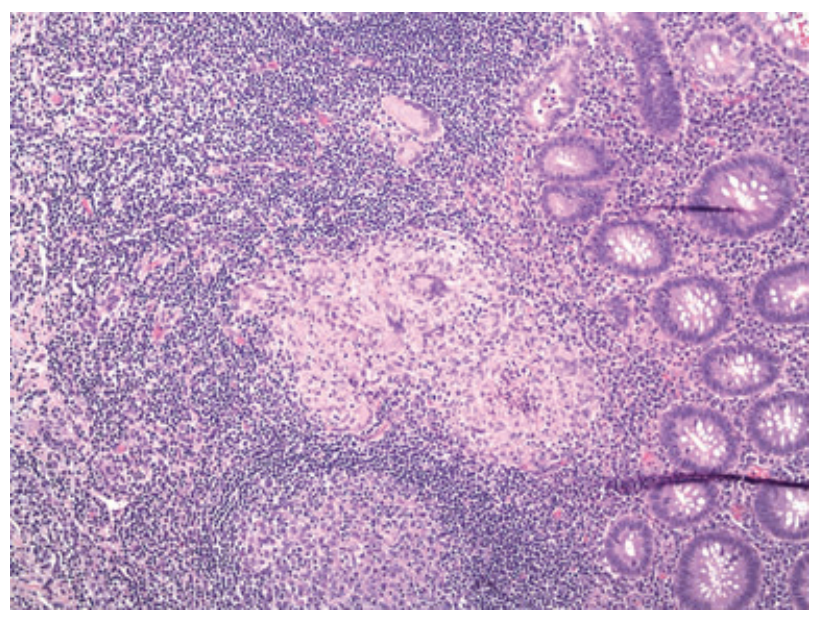

Figure 4. Epithelioid granulomas with prominent lymphoid cuffs in a case of polymerase chain reaction-proven Yersinia enterocolitica (H\&E).

Special stains are not helpful in the diagnosis of Yersinia, for the organisms are small, may be present in low numbers and are difficult to distinguish from normal non-pathogenic colonic flora. Culture, serological studies and PCR assays may be helpful in confirming the diagnosis. ${ }^{20,23}$ The major differential diagnoses for yersiniosis include other infectious processes, particularly Mycobacteria and Salmonella. Acidfast stains and culture results should help to distinguish mycobacterial infection; clinical features and the presence of greater numbers of neutrophils, microabscesses and granulomas may help to distinguish yersiniosis from salmonellosis. Crohn's disease and yersiniosis may be very difficult if not impossible to distinguish from one another histologically. Features that may favour Crohn's include cobblestoning of mucosa and creeping fat grossly, and changes of chronicity microscopically, including crypt distortion, thickening of the muscularis mucosa and prominent neural hyperplasia. However, some cases are indistinguishable on histological grounds. ${ }^{20}$

\section{AEROMONAS SPECIES}

Aeromonas species, initially thought to be non-pathogenic Gram-negative bacteria, are increasingly recognized as causes of gastroenteritis in both children and adults. The motile $A$. hydrophila and $A$. sobria most often cause gastrointestinal disease in humans. The typical presentation is bloody diarrhoea, sometimes chronic, accompanied by nausea, vomiting and cramping pain. The diarrhoea may contain mucus as well as blood. The duration of illness varies widely, ranging 


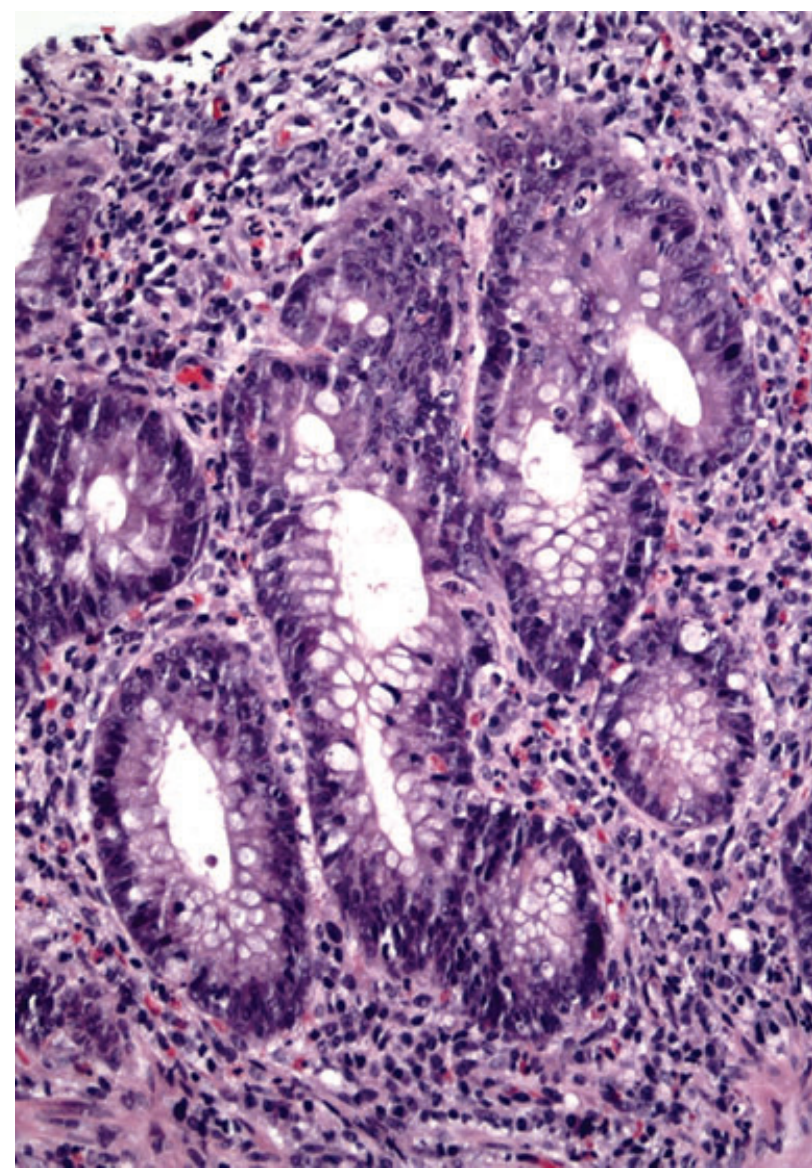

Figure 5. Culture-proven case of Aeromonas infection featuring focal cryptitis and architectural distortion from a right colon biopsy (H\&E).

from a few days to several years, indicating that Aeromonas infection can cause a chronic colitis. ${ }^{24-28}$

Endoscopically, signs of colitis may be seen, including oedema, friability, erosions, exudates and loss of vascular pattern; the features are often segmental and may mimic ischaemic colitis or Crohn's disease. A pancolitis mimicking ulcerative colitis has also been described. The histological features are usually those of acute self-limited colitis. However, ulceration and focal architectural distortion may be seen (Figure 5).

Stool cultures are critical to diagnosis. The differential diagnosis includes other infectious processes, ischaemic colitis and chronic idiopathic inflammatory bowel disease. Culture should help exclude other infections, and typical features of ischaemia (crypt withering, mucosal necrosis) are not present with Aeromonas. When architectural distortion is present in a patient with chronic symptoms, it may be very difficult to resolve the issue of Aeromonas infection versus Crohn's disease or ulcerative colitis. ${ }^{24-28}$ Some authorities recommend culturing for Aeromonas in all patients with refractory chronic inflammatory bowel disease.

ENTAMOEBA HISTOLYTICA

Approximately $10 \%$ of the world's population are infected with this parasite, and the prevalence is much higher in tropical and subtropical locations. Increasingly, male homosexuals are also found to harbour this pathogen. Although some patients suffer a severe, dysentery-like fulminant colitis, many others are asymptomatic or have only vague gastrointestinal symptoms (abdominal pain, diarrhoea with or without blood, and malaise). ${ }^{29}$ Rarely, large inflammatory masses (amoebomas) may be formed.

Grossly, small ulcers are the early lesion, which may coalesce to form large, irregular ulcers that are often geographical or serpiginous. The ulcers often have associated inflammatory exudate or inflammatory polyps. Intervening mucosa is often normal. Ulcers may undermine adjacent mucosa to produce the classic 'flask-shaped' lesion. The caecum is most commonly involved, but any level of the large bowel or appendix may be involved. Fulminant colitis resembling ulcerative colitis, pseudomembranous colitis resembling that caused by $C$. difficile, and toxic megacolon have been described. ${ }^{30}$ Colonoscopy may be normal in asymptomatic patients or those with mild disease. ${ }^{29}$ Histologically, the earliest lesion is a mild neutrophilic infiltrate. In more advanced disease, ulcers are often deep, extending at least into the submucosa, with undermining of adjacent normal mucosa. There is associated necroinflammatory debris; the organisms are generally found within this purulent material. Invasive amoebae are occasionally seen within the bowel wall. The adjacent mucosa is usually normal, but may show gland distortion and inflammation. The organisms, which may be very few in number, resemble macrophages with foamy cytoplasm and a round, eccentric nucleus; the presence of ingested red blood cells is pathognomonic of Entamoeba histolytica. ${ }^{30}$ In patients who are asymptomatic or have mild symptoms, histological changes may be subtle and organisms may be particularly difficult (if not impossible) to find. Invasive amoebiasis is not generally seen in patients with mild or absent symptoms. ${ }^{29}$

The differential diagnosis most often is that of amoebae versus macrophages within an inflammatory exudate. Amoebae are trichrome positive; in addition, macrophages stain with immunostains for $\alpha_{1}$-antitrypsin and chymotrypsin, whereas amoebae do not. Given the not infrequent presence of skip lesions and mucosal architectural distortion, amoebiasis may also be 
confused with Crohn's disease or ulcerative colitis, as well as other types of infectious colitis.

For the diagnostic pathologist, it cannot be overemphasized that Yersinia (enterocolitica and pseudotuberculosis), Salmonella (both non-typhoid and typhoid fever-producing strains), Shigella, Aeromonas and E. histolytica, in addition to the ASLC pattern of inflammation, can produce both gross and histological features that mimic idiopathic inflammatory bowel disease (Table 1). Correlation with clinical presentation, food and water exposure, and culture results can be invaluable tools in resolving this differential diagnosis.

\section{ENTEROHAEMORRHAGIC $E . C O L I$}

The most common strain of enterohaemorrhagic E. coli (EHEC) is 0157:H7, although there are others. This pathogen gained national attention in 1993 when a massive outbreak in the western USA was linked to contaminated hamburger patties. The organism binds intestinal epithelial cells and produces a cytotoxin similar to that produced by Sh. dysenteriae, although there is no invasion. Contaminated meat is the most frequent mode of transmission, but infection may also occur through contaminated water, milk, produce and person-toperson contact. ${ }^{31,32}$

Diarrhoea is usually bloody, with severe abdominal cramps and mild or no fever. Non-bloody, watery diarrhoea may occur, however. Only one-third of patients have faecal leucocytes. Children and the elderly are at particular risk of serious illness, including the haemolytic-uraemic syndrome or thrombotic thrombocytopenic purpura. ${ }^{31,32}$ Endoscopically, patients may have bowel oedema, erosions, ulcers and haemorrhage, and the right colon is usually more severely affected. The oedema may be so marked as to cause obstruction, and surgical resection may be required to relieve this or to control bleeding. The lamina propria and submucosa contain marked oedema and haemorrhage, with associated mucosal acute inflammation, cryptitis, crypt abscesses, ulceration and necrosis. Crypt withering, such as that seen in other causes of ischaemia, is often seen as well. Microthrombi may be seen within small vessels and pseudomembranes are occasionally present (Figure 6). ${ }^{31,32}$

Infection with EHEC is probably markedly underdiagnosed. Routine stool cultures will not distinguish pathogenic strains from normal intestinal flora. If EHEC strains are suspected, the clinical laboratory should be notified to search for them specifically. EHEC are cleared rapidly from stool, often within 4-7 days, thus cultures should be taken as early as possible. Culture

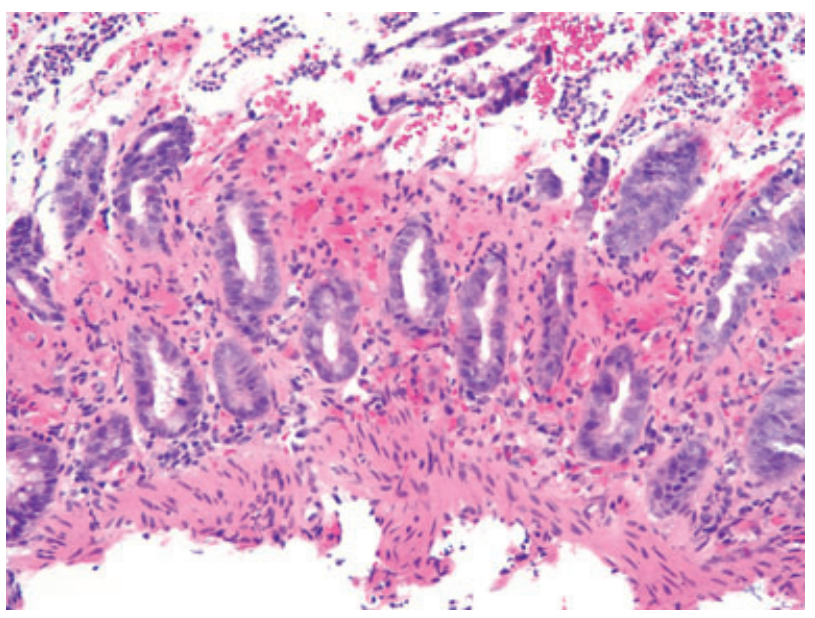

Figure 6. Biopsy from a case of Escherichia coli 0157:H7 showing lamina propria hyalinization, crypt withering, neutrophilic inflammation in the mucosa and fibrin thrombi (H\&E).

and serotyping are the mainstay of laboratory diagnosis; although immunohistochemical stains and molecular assays for EHEC have been described, they are not widely available.

The differential diagnosis of EHEC includes $C$. difficilerelated colitis, idiopathic inflammatory bowel disease, and especially ischaemic colitis. Culture and food intake history may be invaluable. In general, EHEC does not produce the level of mucosal distortion seen in idiopathic inflammatory bowel disease, and lacks granulomas. The histological picture may be very difficult to distinguish from $C$. difficile, and the $C$. difficile antigen test may be very useful. As the cytotoxin produced by EHEC causes ischaemia, the histological features are indistinguishable from ischaemia of other causes.

\section{ENTERIC VIRUSES}

Biopsies from patients with enteric viral infections seldom if ever cross the stage of the surgical pathologist, as they are detected in stool samples rather than biopsy specimens. Some common enteric viruses known to cause diarrhoea include, but are not limited to adenovirus, rotavirus, coronavirus, echovirus, enterovirus, astrovirus and Norwalk virus. Rotavirus is the most common cause of severe childhood diarrhoea and diarrhoeal mortality worldwide, followed by adenoviruses. ${ }^{33}$ Rotavirus infections occur predominantly in infants $<2$ years old. The diarrhoea is usually accompanied by fever and vomiting. Biopsy changes are very non-specific and include increased inflammatory cells in the lamina 
propria, degenerative epithelial changes and swollen villous tips. The diagnosis of rotavirus is generally made by stool immunoassay and/or culture, and the disease is rarely biopsied.

Adenovirus infection is second only to rotavirus as a cause of childhood diarrhoea. However, it has also gained much attention in recent years as a cause of diarrhoea in immunocompromised patients, especially those with HIV and AIDS. Virtually all patients present with diarrhoea, sometimes accompanied by fever, weight loss and abdominal pain. Histological features of adenovirus infection include epithelial changes such as cellular disorder, loss of orientation and degeneration. ${ }^{34}$ Characteristic inclusions may be seen, especially in immunocompromised patients, within the nuclei of surface epithelium (particularly goblet cells). Useful aids to diagnosis of adenovirus infection include immunohistochemistry, stool examination by electron microscopy and viral culture.

Other, less common but well-recognized causes of food and water-related gastrointestinal disease include brucellosis, Bacillus cereus and Listeria monocytogenes. It is also important to remember that many serious food-borne gastrointestinal pathogens may produce little or no inflammatory infiltrate at all, particularly in immunocompromised patients, even in the face of grave clinical disease. These include Vibrio cholerae and non-cholera Vibrio infections, enteropathogenic and enteroadherent $E$. coli and infection with many enteric viruses (Table 1).

\section{Aids to diagnosis of gastrointestinal infectious diseases}

Surgical pathologists may play a very valuable role in the diagnosis of gastrointestinal infectious processes. Once it is determined that an infectious process is in the differential diagnosis, it is very important to alert the clinician, and often the microbiology laboratory, that this is a consideration. In addition to valuable culture techniques, the surgical pathologist's ability to diagnose infectious diseases in tissue sections has grown exponentially in recent years with the advent of new histochemical stains, immunohistochemistry, in situ hybridization and PCR analysis (Table 2). ${ }^{7,20,23,35}$

In summary, infective (including food- and waterborne) gastrointestinal disorders are common, although they are in general underdiagnosed and under-reported. Many of these infections mimic other inflammatory gastrointestinal disease processes, such as ischaemic colitis, Crohn's disease and ulcerative colitis. It is important for surgical pathologists to
Table 2. Selected polymerase chain reaction assays and antibodies useful in diagnosis of infectious agents

\begin{tabular}{llc}
\hline Organism & Antibody & PCR \\
\hline Campylobacter & $\mathrm{X}$ & $\mathrm{X}$ \\
\hline E. coli & $\mathrm{X}$ & \\
\hline Shigella & $\mathrm{X}$ & \\
\hline Salmonella & $\mathrm{X}$ & $\mathrm{X}$ \\
\hline Yersinia & & \\
\hline Rotavirus & $\mathrm{X}$ & \\
\hline Adenovirus & $\mathrm{X}$ & $\mathrm{X}$ \\
\hline Enterovirus & &
\end{tabular}

consider infectious agents in the differential diagnosis as they evaluate inflammatory lesions. The availability of PCR assays and immunohistochemical antibodies for infectious agents is increasing, and these techniques may prove invaluable in associating specific infectious microorganisms with histological patterns of disease, thus facilitating the diagnosis of infectious processes.

\section{References}

1. Surawicz CM. The role of rectal biopsy in infectious colitis. Am. J. Surg. Pathol. 1988; 12 (Suppl. 1); 82-88.

2. Abrams GD. Surgical pathology of the infected gut. Am. J. Surg. Pathol. 1987; 11 (Suppl. 1); 16-24.

3. Greenson JK, Stern RA, Carpenter SL, Barnett JL. The clinical significance of focal active colitis. Hum. Pathol. 1997; 28; 729-733.

4. Kumar NB, Nostrant TT, Appelman HD. The histopathologic spectrum of acute self-limited colitis (acute infectious-type colitis). Am. J. Surg. Pathol. 1982; 6; 523-529.

5. Fang G, Araujo V, Guerrant RL. Enteric infections associated with exposure to animals or animal products. Infect. Dis. Clin. N. Am. 1991; 5; 681-701.

6. Khan AS, Swerdlow DL, Juranek DD. Precautions against biological and chemical terrorism directed at food and water supplies. Public Health Reports 2001; 116; 3-14.

7. Schneider EN, Havens JM, Goldblum JR et al. Molecular detection of Campylobacter infection in cases of focal active colitis. Am. J. Surg. Pathol. 2006; 30; 782-785.

8. Fields PI, Swerdlow DL. Campylobacter jejuni. Clin. Lab. Med. 1999; 19; 489-503.

9. Blaser JM, Parsons RB, Wang WLL. Acute colitis caused by Campylobacter fetus ss. jejuni. Gastroenterology 1980; 78; 448453.

10. Price AB, Jewkes J, Sanderson PJ. Acute diarrhoea: Campylobacter colitis and the role of rectal biopsy. J. Clin. Pathol. 1979; 32; 990997.

11. Kelly JK, Owen DA. Bacterial diarrheas and dystenteries. In Connor DH, Chandler FW, Schwartz DA eds. Pathology of infectious diseases. Stamford, CT: Appleton \& Lange 1997; 421-429. 
12. Pegues DA, Hohmann EL, Miller SI. Salmonella including S. typhi. In Blaser MJ, Smith PD, Ravdin JI eds. Infections of the gastrointestinal tract. New York: Raven Press 1995; 785-809.

13. Kraus MD, Amatya B, Kimula Y. Histopathology of typhoid enteritis: morphologic and immunophenotypic findings. Mod. Pathol. 1999; 12; 949-955.

14. McGovern VJ, Slavutin LJ. Pathology of salmonella colitis. Am. J. Surg. Pathol. 1979; 3; 483-490.

15. Boyd JF. Pathology of the alimentary tract in Salmonella typhimurium food poisoning. Gut 1985; 26; 935-944.

16. Acheson DWK, Keusch GT. Shigella and enteroinvasive E. coli. In Blaser MJ, Smith PD, Ravdin JI eds. Infections of the gastrointestinal tract. New York: Raven Press 1995; 763-784.

17. Mathan MM, Mathan VI. Morphology of rectal mucosa of patients with shigellosis. Rev. Infect. Dis. 1991; 13 (Suppl. 4); S314-318.

18. Speelman P, Kabir I, Islam M. Distribution and spread of colonic lesions in shigellosis: a colonoscopic study. J. Infect. Dis. 1984; 150; 899-903.

19. Naktin J, Beavis KG. Yersinia enterocolitica and Yersina pseudotuberculosis. Clin. Lab. Med. 1999; 19; 523-536.

20. Lamps LW, Madhusudhan KT, Greenson JK et al. The role of $Y$. enterocolitica and $Y$. pseudotuberculosis in granulomatous appendicitis: a histologic and molecular study. Am. J. Surg. Pathol. 2001; 25; 508-815.

21. Gleason TH, Patterson SD. The pathology of Yersinia enterocolitica ileocolitis. Am. J. Surg. Pathol. 1982; 6; 347-355.

22. El-Maraghi NRH, Mair N. The histopathology of enteric infection with Yersinia pseudotuberculosis. Am. J. Clin. Pathol. 1979; 71; 631-639.

23. Lamps LW, Havens JM, Gilbrech LJ, Dube PH, Scott MA. Molecular biogrouping of pathogenic Yersinia enterocolitica: development of a diagnostic PCR assay with histological correlation. Am. J. Clin. Pathol. 2006; 125; 658-664.
24. Deutsch SF, Wedzina W. Aeromonas sobria associated left sided segmental colitis. Am. J. Gastroenterol. 1997; 92; 21042106.

25. Travis LB, Washington JA. The clinical significance of stool isolates of Aeromonas. Am. J. Clin. Pathol. 1986; 85; 330-336.

26. Yarze JC. Aeromonas as a cause of segmental colitis. Am. J. Gastroenterol. 1998; 93; 1012-1013.

27. Gracey M, Burke V, Robinson I. Aeromonas-associated gastroenteritis. Lancet 1982; 2; 1304-1306.

28. George WL, Nakata MM, Thompson J, White ML. Aeromonasrelated diarrhea in adults. Arch. Int. Med. 1985; 145; 22072211.

29. Variyam EP, Gogate P, Hassan M et al. Nondysenteric intestinal amebiasis: colonic morphology and search for Entamoeba histolytica adherence and invasion. Dig. Dis. Sci. 1989; 34; 732740.

30. Brandt H, Tamayo P. Pathology of human amebiasis. Hum. Pathol. 1970; 1; 351-385.

31. Kelly J, Oryshak A, Wenetsek M, Grabiec J, Handy S. The colonic pathology of E. coli 0157:H7 infection. Am. J. Surg. Pathol. 1990; 14; 87-92.

32. Griffin PM, Olmstead LC, Petras RE. Escherichia coli 0157:H7associated colitis: a clinical and histological study of 11 cases. Gastroenterology 1990; 99; 142-149.

33. Hibbs RG. Diarrhoeal disease: current concepts and future challenges. Trans. Roy. Soc. Trop. Med. Hyg. 1993; 87 (Suppl. 3); $1-2$.

34. Yan Z, Nguyen S, Poles M, Melamed J, Scholes JV. Adenovirus colitis in human immunodeficiency virus infection: an underdiagnosed entity. Am. J. Surg. Pathol. 1998; 22; 11011106.

35. Scott MA. Infections involving lymph nodes. In Collins RD, Swerdlow SH eds. Pediatric hematopathology. New York: Churchill Livingstone 2001; 289-312. 